\title{
Taxonomy of the genus Neopanorpa van der Weele, 1909 (Mecoptera, Panorpidae) from the Oriental Region, with the description of two new species
}

\author{
Ji-Shen WANG ${ }^{1} \&$ Bao-Zhen HUA ${ }^{2, *}$ \\ ${ }^{1,2}$ Key Laboratory of Plant Protection Resources and Pest Management, Ministry of Education, \\ Entomological Museum, Northwest A\&F University, Yangling, Shaanxi 712100, China. \\ *Corresponding author: huabzh@nwafu.edu.cn \\ 1Email: wangjs@nwafu.edu.cn \\ ${ }^{1}$ urn:lsid:zoobank.org:author:0C4FE92F-97C9-427C-B5F4-762A93A837EC \\ ${ }^{2}$ urn:lsid:zoobank.org:author:C02F1E14-1B20-4B92-BA8F-57937D3D3137
}

\begin{abstract}
Neopanorpa van der Weele, 1909 is the second largest genus in Panorpidae, and over 170 Oriental species have been reported hitherto. In this paper, we describe two new species: Neopanorpa luojishana sp. nov. and Neopanorpa xingmini sp. nov. from Southwest China. We also report the first discovery of the male of Neopanorpa ocellaris (Navás, 1908) from Guangxi and Guizhou, China, a species recorded from Sikkim previously. Neopanorpa brevivalvae Chou \& Wang, 1988 is synonymized with Neopanorpa lungtaushana Cheng, 1957. In addition, Neopanorpa furcula nom. nov. is proposed for Neopanorpa furcata Zhou, 2005, a junior homonym preoccupied by Neopanorpa furcata (Hardwicke, 1825). The biogeographical implications of some Neopanorpa species are discussed in brief.
\end{abstract}

Keywords. Diversity, new species, scorpionflies, taxonomy, synonym.

Wang J.-S. \& Hua B.-Z. 2019. Taxonomy of the genus Neopanorpa van der Weele, 1909 (Mecoptera, Panorpidae) from the Oriental Region, with the description of two new species. European Journal of Taxonomy 543: 1-17. https://doi.org/10.5852/ejt.2019.543

\section{Introduction}

Panorpidae Latreille, 1805 are the largest extant mecopteran family with over 490 species distributed in the Holarctic and Oriental Regions (Penny \& Byers 1979; Bicha 2018; Wang \& Hua 2019). The adults are commonly called 'scorpionflies' due to the enlarged and recurved male genitalia, which resemble the stinger of scorpions (Byers \& Thornhill 1983). Eight genera are assigned to Panorpidae hitherto: Cerapanorpa Gao, Ma \& Hua, 2015 (19 spp.), Dicerapanorpa Zhong \& Hua, 2013 (18 spp.), Furcatopanorpa Ma \& Hua, 2012 (1 sp.), Leptopanorpa MacLachlan, 1887 (12 spp.), Megapanorpa Wang \& Hua, 2019 (5 spp.), Neopanorpa van der Weele, 1909 (ca 170 spp.), Panorpa Linnaeus, 1758 (ca 260 spp.), and Sinopanorpa Cai \& Hua, 2008 (3 spp.). 
The Oriental Neopanorpa was established as a subgenus of Panorpa initially, and later raised to the generic status by Esben-Petersen (1913). Neopanorpa and Leptopanorpa resemble each other by their slender rostrum, relatively narrow wing base in both sexes, and a greatly developed notal organ in the males. In general, these two genera can be differetiated from all the other genera in Panorpidae by the vein $1 \mathrm{~A}$ ending proximal to the origination of Rs, and a single crossvein between $1 \mathrm{~A}$ and $2 \mathrm{~A}$ in the forewings (Issiki 1933; Cheng 1957a; Wang \& Hua 2019). However, these two characters can also be infrequently observed in Panorpa, and are not strictly reliable criteria in the generic division (Hua et al. 2018). The sister-group relationship between a subset of Neopanorpa and Leptopanorpa was proposed by Willmann (1989) based on morphological comparisons, and corroborated by recent morphological (Ma et al. 2012) and molecular phylogenetic analyses (Miao et al. 2019). These results indicate that Neopanorpa is a paraphyletic group, forming a monophyletic clade together with Leptopanorpa, hence more detailed research into Neopanorpa is urgently needed (Miao et al. 2019).

There are 21 species of Neopanorpa recorded from the Indian Subcontinent and Himalayas (Rust \& Byers 1976), 37 species from the Indochinese Peninsula (Byers 1965, 1999; Bicha 2015; Bicha et al. 2017), one species from the Ryukyu Islands, Japan (Miyamoto \& Makihara 1979), and 15 species from the Indonesian and Malaysian Islands (Byers 1966; Chau \& Byers 1978), while the greatest species diversity with 102 species is recorded from China (Wang \& Hua 2017, 2018a, 2018b). Among them, several frontier species have been recorded in adjoining countries, such as Neopanorpa chillcotti Byers, 1971 from Nepal and Tibet, China; N. harmandi (Navás, 1908) from Thailand and Yunnan, China; and N. nielseni Byers, 1965 from Vietnam and Yunnan, China (Wang \& Hua 2017).

In this paper, we describe two new species, Neopanorpa luojishana sp. nov. from Sichuan and N. xingmini sp. nov. from Yunnan, China. We also provide the first complete account of the male characters of N. ocellaris (Navás, 1908), a species only recorded from Sikkim previously but recently discovered from Guangxi and Guizhou, China. Neopanorpa brevivalvae Chou \& Wang, 1988 is synonymized with $N$. lungtaushana Cheng, 1957. In addition, $N$. furcula nom. nov. is proposed for $N$. furcata Zhou, 2005, a junior homonym preoccupied by $N$. furcata (Hardwicke, 1825). By comparisons with adjoining faunas, the biogeographical implications of some Neopanorpa species are discussed in brief.

\section{Material and methods}

All examined specimens are stored in the Entomological Museum, Northwest A\&F University, Yangling or Sun Yat-Sen University, Guangzhou.

Specimens were observed and dissected under a Nikon SMZ 1500 Stereoscopic Zoom microscope (Nikon, Tokyo, Japan). Measurements of right wings were made with a vernier caliper. The lengths of the wings were measured as the linear distance from the middle of the wing base to the apex, and widths from the ending of $\mathrm{M}_{4}$ to the costal margin vertically. Some parts of genitalia were macerated in boiling $10 \% \mathrm{NaOH}$ solution and then rinsed with tap water. Photographs were taken with a Nikon D7000 digital camera. The distribution map was obtained from Maps-For-Free (https://maps-for-free.com) and modified with Adobe Illustrator CC. All pictures were adjusted and assembled into plates with Adobe Photoshop CS4. Terminology follows Mickoleit (1976), Gao et al. (2016) and Wang \& Hua (2019).

\section{Repositories}

NWAU $=$ Entomological Museum, Northwest A\&F University, Yangling

SYSU $=$ Sun Yat-Sen University, Guangzhou 


\section{Abbreviations}

The following abbreviations and acronyms are applied in the main text:
A1 = first abdominal segment (and so forth for other segments)
$\mathrm{T} 1=$ first tergum (and so forth for other segments)
$\mathrm{FL}=$ length of forewing
$\mathrm{FW}=$ width of forewing
$\mathrm{HL}=$ length of hindwing
HW $=$ width of hindwing

The following abbreviations and acronyms are applied in the figure annonations:
ap $\quad=$ apodeme of axis
ax $=$ axis
$\mathrm{dbp}=$ dorsal bridge of paramere
$\mathrm{dpr}=$ dorsal process
$\mathrm{dv}=$ dorsal valve
ep $=$ epandrium
epl $=$ epandrial lobe
$\mathrm{gcx}=$ gonocoxite
gs $=$ gonostylus
hpp $=$ hypandrial process
hv $=$ hypovalve
lpr $=$ lateral process
no $=$ notal organ
$\mathrm{pa}=$ posterior arm
$\mathrm{pm}=$ paramere
pno $=$ postnotal organ
sth $=$ stalk of hypovalve
stp $=$ stalk of paramere
$\mathrm{vv}=$ ventral valve

\section{Results}

Class Insecta Linnaeus, 1758

Order Mecoptera Packard, 1886

Family Panorpidae Latreille, 1805

Genus Neopanorpa van der Weele, 1909

Neopanorpa van der Weele, 1909: 4. Type species: Panorpa angustipennis Westwood, 1841, original designation.

Neopanorpa luojishana Wang \& Hua sp. nov. urn:1sid:zoobank.org:act:BA7EB27E-29A8-4098-BE84-583D16E82B6C

Figs $1-2$

\section{Diagnosis}

The new species can be recognized by the following features: 1) vertex yellowish brown with a broad black stripe enclosing ocellar triangle and extending to occiput (Fig. 2C); 2) wings nearly lacking markings except distinctly reduced apical and pterostigmal bands (Figs 1, 2A-B); in males, 3) notal 
organ well-developed, slender stick-like and extending slightly beyond posterior border of T5 (Figs 1, 2A, D); 4) three postnotal organs on T4-T6, respectively (Fig. 2D); 5) genital bulb distinctly elongated, over two times as long as wide (Fig. 2E-F); 6) gonostylus bearing a tuft of long stout setae on middle of ventral surface (Fig. 2F-G); and in females, 7) medigynium with long axis nearly two-thirds of total length, and greatly divergent apodemes (Fig. 2L).

\section{Etymology}

The new species is named after the type locality, Luojishan (= Mt. Luoji).

\section{Material examined}

\section{Holotype}

CHINA - ${ }^{\prime}$; Sichuan, northern slope of Mt. Luoji; $27^{\circ} 40.69^{\prime}$ N, $102^{\circ} 18.28^{\prime}$ E; 2700 m a.s.1; 30 Jun. 2016; Ji-Shen Wang leg.; NWAU.

\section{Paratypes}

CHINA • 1 `; Sichuan, western slope of Mt. Luoji; $27^{\circ} 34.75^{\prime} \mathrm{N}, 102^{\circ} 14.67^{\prime} \mathrm{E} ; 2200 \mathrm{~m}$ a.s.1; 29 Jun. 2016; Ji-Shen Wang leg.; NWAU • $2 \widehat{\partial} \widehat{\partial}, 2$ 우; same data as for holotype; NWAU.

\section{Description}

\section{Male}

Measurements. Holotype: $\mathrm{FL}=13.6 \mathrm{~mm}, \mathrm{FW}=2.9 \mathrm{~mm} ; \mathrm{HL}=12.4 \mathrm{~mm}, \mathrm{HW}=2.8 \mathrm{~mm}$. Other specimens: $\mathrm{FL}=13.2-13.6 \mathrm{~mm}, \mathrm{FW}=2.8-2.9 \mathrm{~mm} ; \mathrm{HL}=12.2-12.5 \mathrm{~mm}, \mathrm{HW}=2.7-2.8 \mathrm{~mm}$.

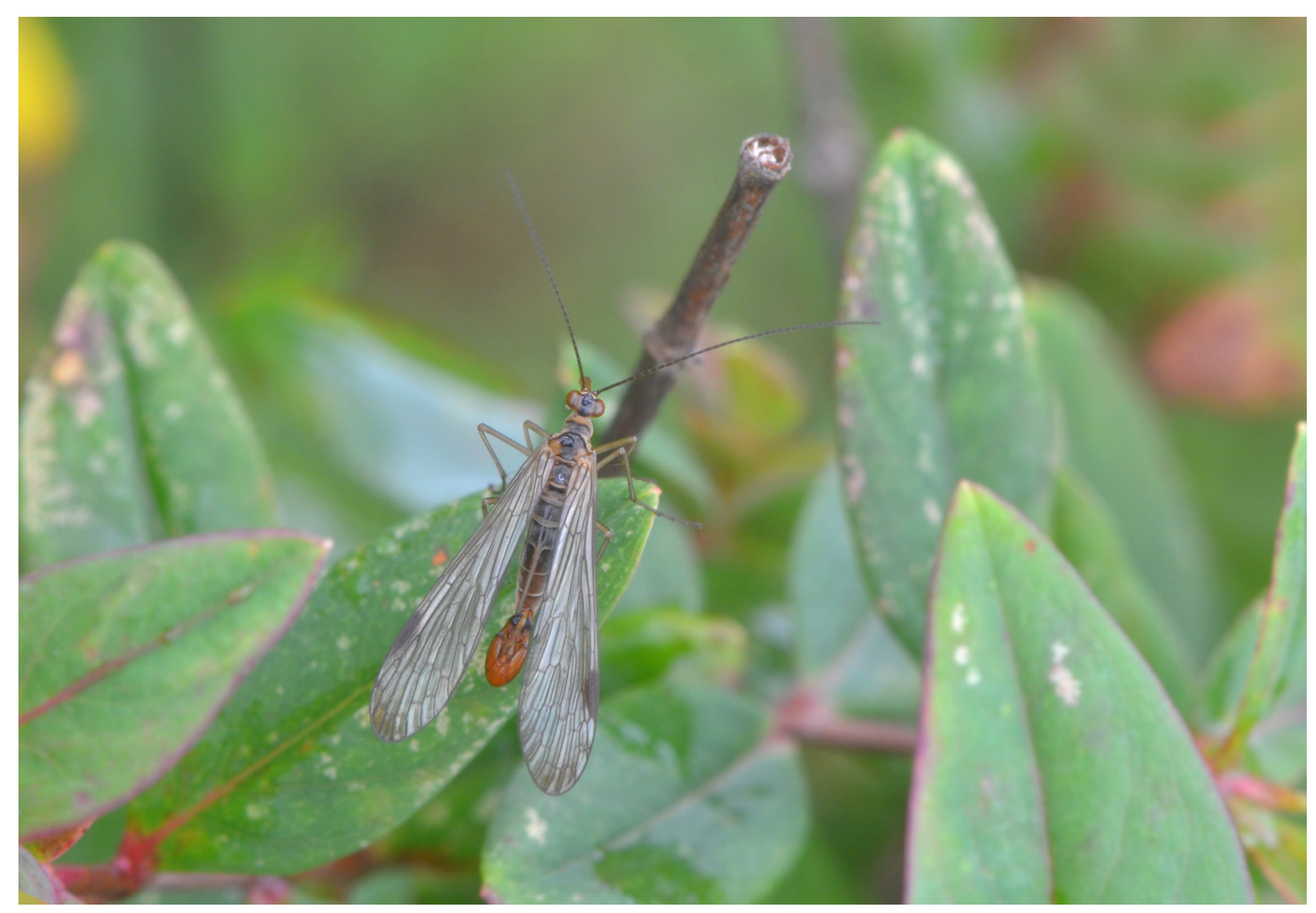

Fig. 1. Neopanorpa luojishana Wang \& Hua sp. nov., living male. Photo by Ji-Shen Wang from Mt. Luoji, Sichuan, China. 
HEAD (Fig. 2C). Vertex yellowish brown laterally, with broad black stripe enclosing ocellar triangle and extending to occiput. Frons dark yellowish brown. Rostrum sordidly yellowish brown with two faint dark stripes along clypeus; labrum dark yellowish brown. Maxillary and labial palps yellowish brown basally and gradually darkening toward apical segment. Scape yellowish brown, pedicel dark yellowish brown; flagellomeres 40, yellowish brown in several basal segments and gradually darkening toward apex.

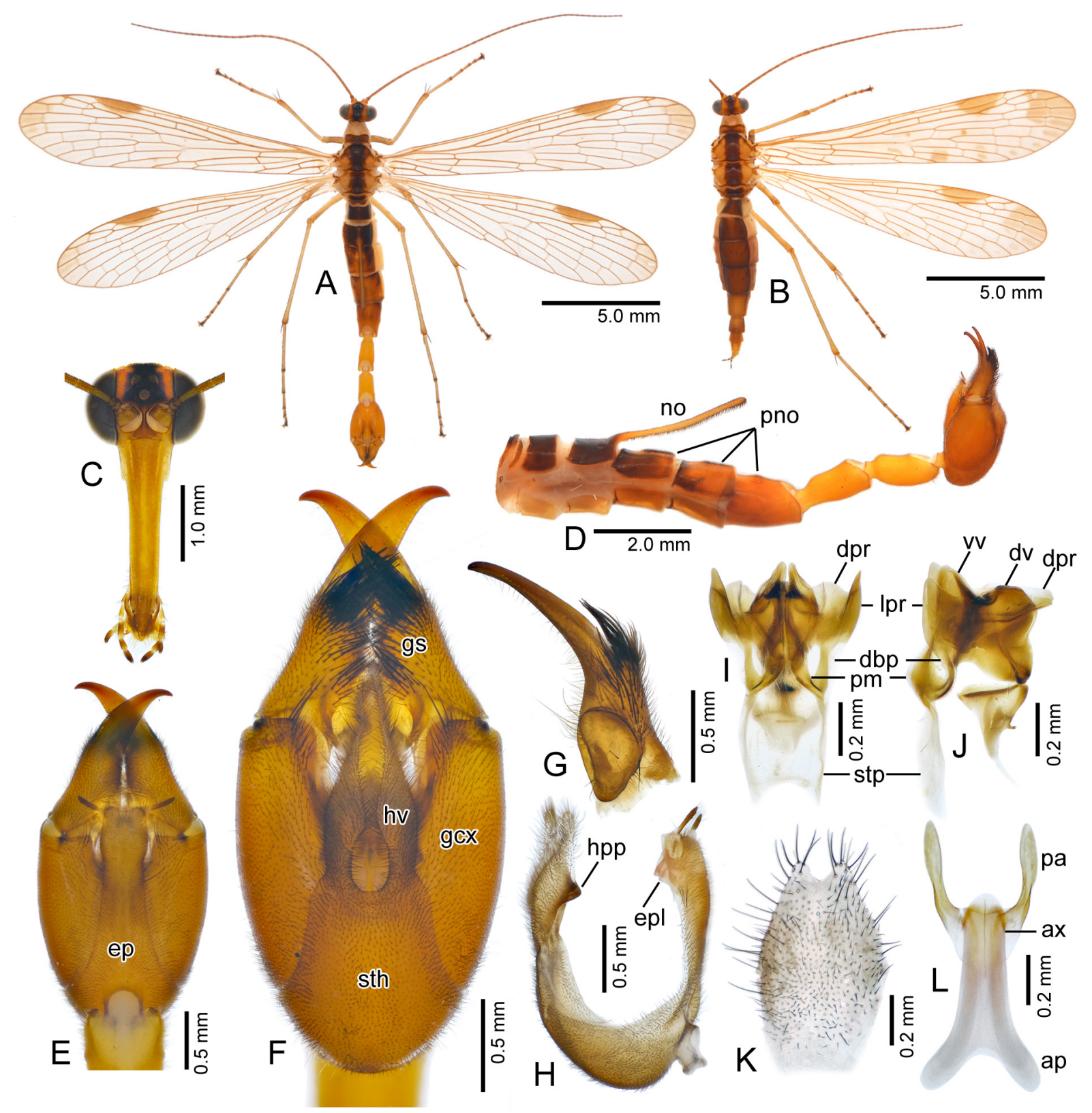

Fig. 2. Neopanorpa luojishana Wang \& Hua sp. nov., paratypes (NWAU). A, C-J. Male. A. Habitus, dorsal view. C. Head, frontal view. D. Abdomen, left-lateral view. E-F. Genital bulb, dorsal and ventral views, respectively. G. Right gonostylus, left-lateral view. H. Epandrium and hypandrium, rightlateral view. I-J. Aedeagal complex, ventral and right-lateral views, respectively. - B, K-L. Female. B. Habitus, dorsal view. K. Subgenital plate, ventral view. L. Medigynium, ventral view. 
Thorax (Fig. 2A). Pronotum dark yellowish brown, with 6-10 stout setae along anterior margin. Mesonotum dark brown anteriorly and mesally, and bearing two large light yellowish brown spots near wing bases; metanotum similar to mesonotum but with larger light yellowish brown spots laterally; scutella dark brown. Pleura and legs light yellowish brown.

Wings (Fig. 2A). Wing membrane slightly tinged with yellowish brown, hyaline with greatly reduced markings; pterostigma brown and distinct; veins dark brown except whitish crossveins in apical half. Forewing with greatly reduced apical band between $\mathrm{R}_{2 \mathrm{~b}}$ and $\mathrm{R}_{5}$; pterostigmal band only flattened semicircular stripe on pterostigma; other markings absent; in some individuals small faint spot at ending of $\mathrm{CuA} ; \mathrm{R}_{2 \mathrm{a}}$ shortly bifurcated. Hindwing similar to forewings in shape and venation, with much more reduced apical band.

ABdomen (Fig. 2A, D). T2 dark brown; T3 mostly dark brown and yellowish brown on posterior margin; T4 and T5 dark brown anteriorly and yellowish brown posteriorly. Notal organ on hind margin of T3 slender, with apex slightly beyond posterior margin of T5, and bearing dense short setae on ventral surface. Postnotal organs represented by three discontinuous, hirsute ridges on T4-T6, respectively. A6 yellowish brown, slightly longer than A5 and tapering toward apex, and emarginate in U-shape at apex dorsally. A7 slightly shorter than A6, distinctly constricted at one-fifth of base and slightly beveled apically. A8 shorter than A7, distinctly constricted at base, humped ventrally, and beveled apically.

Genitalia (Fig. 2E-J). Genital bulb long ellipsoidal, over two times as long as wide. Epandrium narrow, slightly emarginate at apex; epandrial lobes truncate with hook-shaped caudal corner. Hypandrium with broad basal stalk and split into paired hypovalves at middle; hypovalve long fusiform and hirsute, with slender apex; hypandrial processes triangular. Gonocoxite bearing several long and stout setae on inner side of apex ventrally. Gonostylus shorter than gonocoxite, slightly concave at outer margin near base, greatly curved dorsad in apical half, and bearing a tuft of black, long and stout setae at middle of ventral surface; median tooth on inner margin barely raised; basal process large, distinctly concaved. Parameres slender, convergent apically, with basal stalks fused into sclerotized frame; dorsal bridge greatly sclerotized, curved and connected to base of lateral processes. Ventral aedeagal valves conical; dorsal valves short and blunt; dorsal processes broad with a longitudinal ridge; lateral processes distinctly bending caudally, with acute apex almost at same level of ventral valves.

\section{Female}

Similar to males in body coloration except denser wing markings (Fig. 2B). In forewing, apical band broad between $\mathrm{R}_{2 \mathrm{a}}$ and $\mathrm{R}_{5}$; three additional small stripes between $\mathrm{R}_{5}$ and $\mathrm{M}_{3}$; pterostigmal band shattered into several parts: large semicircular spot on pterostigma, small rounded spot enclosing nygma anterior to $\mathrm{M}_{1}$, large irregular spot near ending of $\mathrm{CuA}$, and two small spots near ending of $\mathrm{M}_{4}$. Two small spots each enclosing nygma anterior to thyridium, and near ending of $\mathrm{CuP}$, respectively. Hindwing similar to forewings in shape and venation but with much more reduced markings.

Measurements. $\mathrm{FL}=13.6-13.7 \mathrm{~mm}, \mathrm{FW}=2.8-2.9 \mathrm{~mm} ; \mathrm{HL}=12.3-12.5 \mathrm{~mm}, \mathrm{HW}=2.7-2.8 \mathrm{~mm}$.

Genitalia (Fig. 2K-L). Subgenital plate oval, with V-shaped emargination at apex. Medigynium with long axis approximately two-thirds as long as total length, apodemes greatly divergent at base; posterior arms slender, approximately one-third as long as medigynium, twisted subbasally, and slightly spatulate apically.

\section{Distribution}

China: southern Sichuan. 


\section{Comments}

Neopanorpa luojishana sp. nov. bears three postnotal organs on T4-T6 (Fig. 2D), respectively, greatly resembling N. dorsalis Byers, 1965 from Dalat, southern Vietnam, N. longistipitata Wang \& Hua, 2018 from Dali, northwestern Yunnan, and N. setigera Wang \& Hua, 2018 from Shimian, western Sichuan, China. By contrast, most other Neopanorpa species only bear a single postnotal organ on T4.

Neopanorpa xingmini Wang \& Hua sp. nov. urn:lsid:zoobank.org:act:77CF0A4F-5264-49AF-B624-8D10622DAB38

Fig. 3

\section{Diagnosis}

The new species can be recognized by the following features: 1) bearing special wing markings, with apical and pterostigmal bands connected along anterior margin, and an elongated oblique marginal spot (Fig. 3A-B); in males, 2) notal organ well-developed, slender, stick-like and extending slightly beyond the middle of A6 (Fig. 3D); 3) hypovalves distinctly curled ventrad (Fig. 3H-I); and 4) hypandrial processes curved and finger-like (Fig. 3F, I).

\section{Etymology}

The specific epithet is dedicated to the collector of the type specimens, Xing-Min Wang.

\section{Material examined}

\section{Holotype}

CHINA • ^’; Yunnan; Longchuan County, Husa; 24 May 2008; Xing-Min Wang leg.; NWAU.

\section{Paratypes}

CHINA $\bullet 2 \precsim ふ, 1$ + ; same data as for holotype; NWAU.

\section{Description}

\section{Male}

Measurements. Holotype: $\mathrm{FL}=11.4 \mathrm{~mm}, \mathrm{FW}=2.3 \mathrm{~mm} ; \mathrm{HL}=10.5 \mathrm{~mm}, \mathrm{HW}=2.2 \mathrm{~mm}$. Other specimens: $\mathrm{FL}=11.3-11.5 \mathrm{~mm}, \mathrm{FW}=2.3-2.4 \mathrm{~mm} ; \mathrm{HL}=10.3-10.4 \mathrm{~mm}, \mathrm{HW}=2.2-2.3 \mathrm{~mm}$.

HEAD (Fig. 3C). Vertex dark brown. Frons and hind margin of antennal sockets light yellowish brown. Rostrum sordidly yellowish brown with two faint dark stripes along clypeus. Maxillary and labial palps mostly yellowish brown with terminal segment dark brown. Scape light yellowish brown, pedicel dark brown; flagellomeres 43 , black.

Thorax (Fig. 3A). Pronotum dark brown, with 10 black stout setae on anterior margin. Mesonotum black anteriorly and mesally, with two large light yellowish brown spots near wing bases; metanotum similar to mesonotum but with larger light yellowish brown spot laterally; scutella brown. Pleura light yellowish brown. Legs light yellowish brown, slender.

Wings (Fig. 3A). Wing membrane faintly tinged with yellow, hyaline; markings brown; pterostigma light brown; veins brown, except whitish crossveins in apical half. Forewing with broad apical and pterostigmal bands; apical band greatly projected at inner margin, and connected to pterostigmal band along costal margin; pterostigmal band complete, with basal branch approximately two times as broad as apical branch; elongated marginal spot oblique, almost connected to basal branch of pterostigmal band posteriorly, forming N-shaped pattern; basal band split into two irregular spots; $\mathrm{R}_{2 \mathrm{a}}$ simple. 
Hindwing similar to forewings in shape and venation, but lacking marginal spot; basal band represented by indistinct spot between $\mathrm{CuA}$ and $\mathrm{CuP}$.

Aвdomen (Fig. 3A, D). A1-A5 sordidly dark yellowish brown, A7-A9 yellowish brown. Notal organ on posterior margin of $\mathrm{T} 3$ well-developed, slender, stick-like and extending slightly beyond middle portion of A6, distinctly curved dorsad in apical half, and bearing numerous short setae on ventral surface.

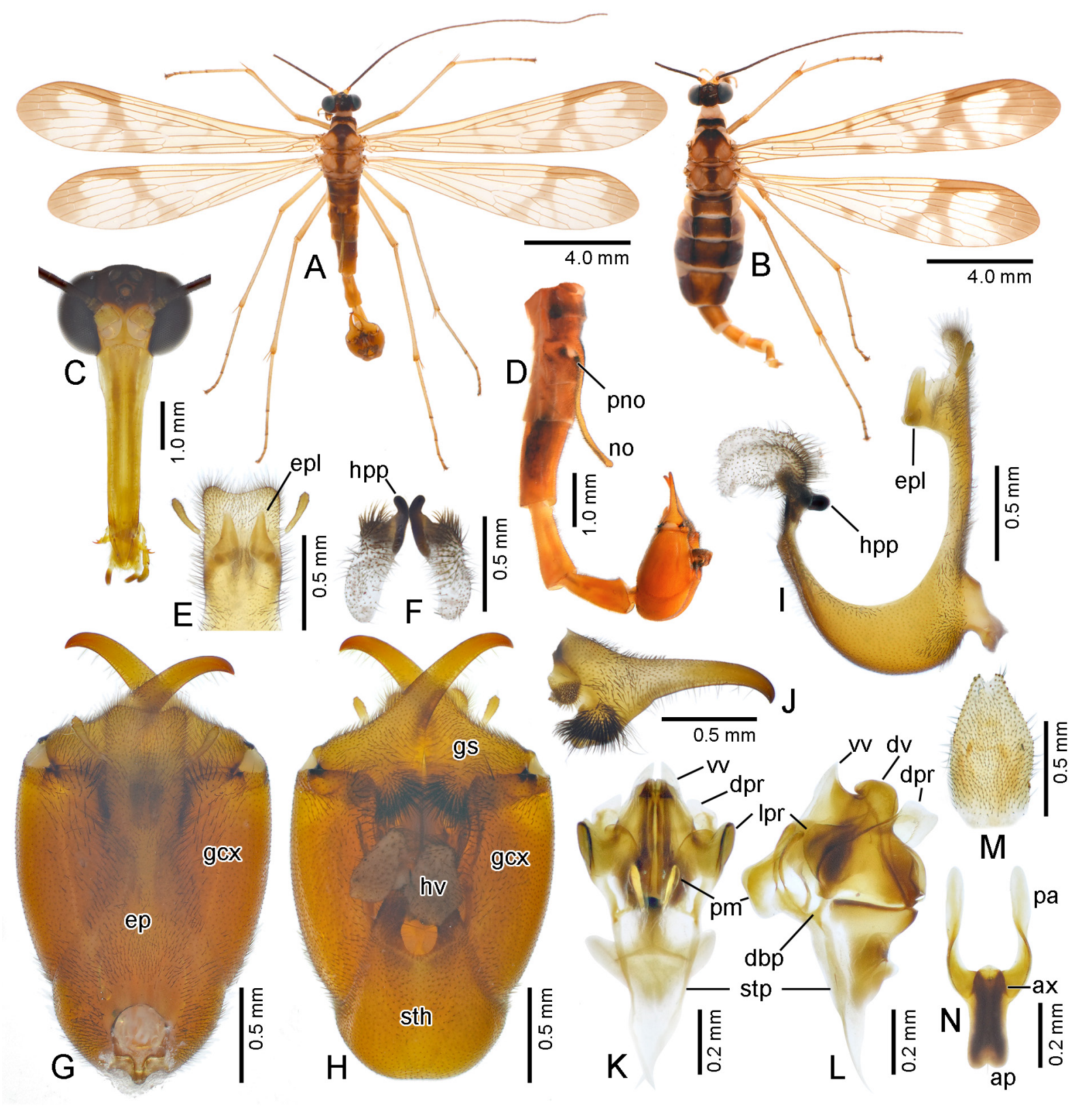

Fig. 3. Neopanorpa xingmini Wang \& Hua sp. nov., paratypes (NWAU). A, C-L. Male. A. Habitus, dorsal view. C. Head, frontal view. D. Abdomen, left-lateral view. E. Apical portion of epandrium, ventral view. F. Hypovalves, caudal view. G-H. Genital bulb, dorsal and ventral views, respectively. I. Epandrium and hypandrium, right-lateral view. J. Left gonostylus, ventral view. K-L. Aedeagal complex, ventral and right-lateral views, respectively. $-\mathbf{B}, \mathbf{M}-\mathbf{N}$. Female. B. Habitus, dorsal view. M. Subgenital plate, ventral view. N. Medigynium, ventral view. 
T4 with membranous area before barely raised postnotal organ. A6 approximately two times as long as A5, cylindrical. A7 slightly shorter than A6, slightly enlarged toward truncated apex; A8 shorter than A7 with beveled apex.

Genitalia (Fig. 3E-L). Genital bulb bold and oval, widest near apex of gonocoxites. Epandrium narrow, truncated at apex; epandrial lobes boot-shaped with tapering apex, and greatly convergent. Hypandrium with broad basal stalk and split into a pair of hypovalves apically; hypandrial processes slender, fingerlike, slightly curved laterad apically; hypovalves mostly whitish but black at base, hirsute and greatly curled ventrad. Gonostylus concaved near basal one-third on outer margin; median tooth barely raised; basal process large and setose. Parameres flat, distinctly projected ventrad, with slightly sclerotized dorsal bridge connected to base of lateral processes. Ventral aedeagal valves with acute and translucent apexes; dorsal valves blunt and shorter than ventral valves; dorsal processes broad and translucent; lateral processes broad and rounded apically.

\section{Female}

Similar to males in body colors but with denser wing markings (Fig. 3B). In forewings, apical band extending to ending of $\mathrm{M}_{3}$ posteriorly; marginal spot dense and distinctly connected to basal branch of pterostigmal band; a small irregular spot on Sc between marginal spot and pterostigmal band.

Measurements. FL $=12.4 \mathrm{~mm}, \mathrm{FW}=2.4 \mathrm{~mm} ; \mathrm{HL}=11.3 \mathrm{~mm}, \mathrm{HW}=2.3 \mathrm{~mm}$.

Genitalia (Fig. 3M-N). Subgenital plate long and suboval, with shallow V-shaped emargination apically. Medigynium with axis slightly shorter than half of total length, parallel apodemes densely sclerotized; posterior arms slightly longer than axis, distinctly twisted medially and slightly spatulate in apical half.

\section{Distribution}

China: western Yunnan.

\section{Comments}

Although N. xingmini sp. nov. resembles N. luojishana sp. nov. in the well-developed male notal organ, it lacks the modified postnotal organs on A5 and A6 (Fig. 3D). It is similar to the Tibetan species N. tibetensis Hua \& Chou, 1999 superficially, but can be distinguished from the latter by the smaller size with a maximum male FL of $11.5 \mathrm{~mm}$ (cf. exceeding $14.5 \mathrm{~mm}$ ), the innerly projected apical band (cf. simple), and the details of the male and female genitalia. The female medigynium of $N$. xingmini sp. nov. resembles that of $N$. triangulata Wang \& Hua, 2018 from Yunnan, N. liquifasciata Byers, 1999 and N. similis Byers, 1999 from Kachin, northern Myanmar, but the unique wing markings and welldeveloped male notal organ make the new species distinctive.

\section{Neopanorpa ocellaris (Navás, 1908)}

Figs $4-5$

Panorpa ocellaris Navás, 1908: 417, fig. 22 (type locality: Sikkim).

Neopanorpa ocellaris - Esben-Petersen 1921: 82, fig. 92. — Rust and Byers 1976: 62, figs 79-80.

\section{Diagnosis}

This species is peculiar among its congeners by the wing markings (Figs 4, 5A-B): all bands and spots intensively fused to each other to form a distinctive zigzag pattern, leaving several dentate hyaline spots along anterior and posterior margins, and an elliptical hyaline spot between pterostigmal and apical bands. 


\section{Material examined}

CHINA - Guangxi • 1 § ; Longzhou County, Nonggang; 3 Jun. 1980; Zhu-Yin Wang leg.; NWAU • 1 \&; Ningming County, Longrui; 200 m a.s.1.; 23 May 1984; Ji-Zhen Wang leg.; NWAU. - Guizhou, Libo County • 2 우; Dongdai; 24 Apr. 2017; Ri-Xin Jiang \& Zhuo-Heng Jiang leg.; NWAU • 2 ふふ Bizuo; 29 Apr. 2017; Ri-Xin Jiang \& Zhuo-Heng Jiang leg.; NWAU • 1 ô. 4 q $O$; Shishangsenlin; $25^{\circ} 17.25^{\prime} \mathrm{N}, 107^{\circ} 56.35^{\prime}$ E; 700 m a.s.1.; 24 May 2018; Gui-Lin Hu \& Ning Li. leg.; NWAU.

\section{Description}

\section{Male}

MeAsurements. $\mathrm{FL}=13.5-15.0 \mathrm{~mm}, \mathrm{FW}=3.0-3.4 \mathrm{~mm} ; \mathrm{HL}=12.0-13.2 \mathrm{~mm}, \mathrm{HW}=2.8-3.2 \mathrm{~mm}$.

HEAD (Fig. 5D). Vertex black. Rostrum dark reddish brown, with two dark stripes along clypeus. Maxillary and labial palps dark reddish brown with distal segment dark brown. Antennae black, flagellomeres $42-44$.

Thorax (Fig. 5A). Pronotum black, with 10-16 stout setae along anterior margin. Meso- and metanotum black. Membranous area yellow. Pleura and coxae dark chestnut to black; femora and tibiae yellowish brown; tarsi blackish brown.

WINGS (Fig. 5A). Wing membrane hyaline, with well-developed dark brown markings; veins dark brown except whitish cross-veins in apical half; pterostigma brown. Forewing apical band very broad and fused to pterostigmal band anteriorly and posteriorly, forming elliptical hyaline spot; pterostigmal band

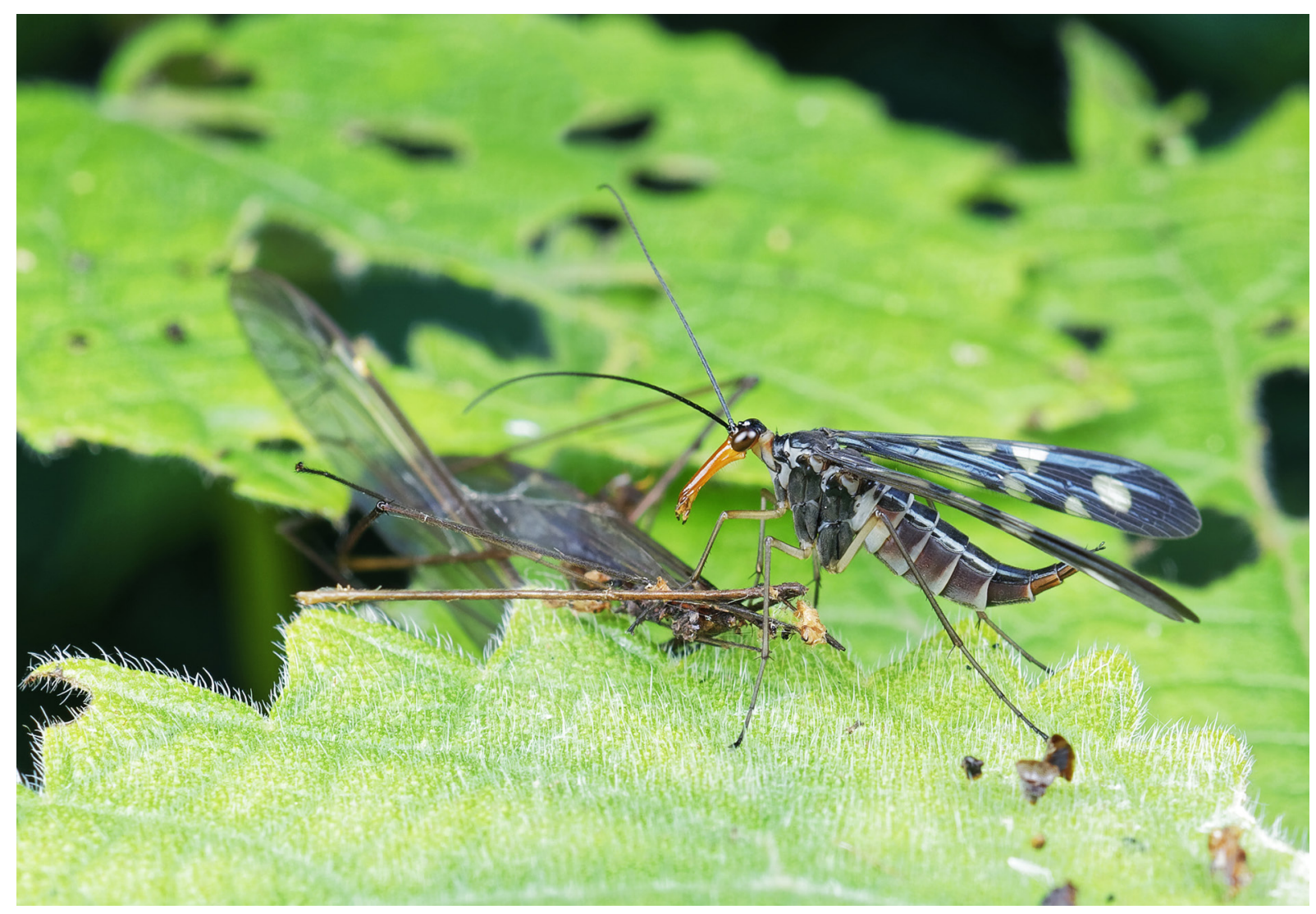

Fig. 4. Neopanorpa ocellaris (Navás, 1908), living female. The female is feeding on a dead crane fly. Photo by Wei-Liang Xie from Huanjiang County, Guangxi Province, China. 
broad, with basal branch approximately two times as wide as apical branch; marginal spot elongated posteriorly, fused with basal branch of pterostigmal band apically, and with basal band basally; basal band and spot completely fused, and forming broad irregular stripe extending to anal area; $\mathrm{R}_{2}$ trifurcated. Hindwing similar to forewings in shape and venation, but basal band and spot slightly reduced.

Abdomen (Fig. 5A, G). A2-A8 with terga and sterna entirely dark chestnut to black, membranous area yellow to pale yellowish brown. Notal organ on posterior border of T3 triangular in basal half, fingerlike in distal half, and extending to middle portion of T4; postnotal organ on T4 blunt. A6 approximately

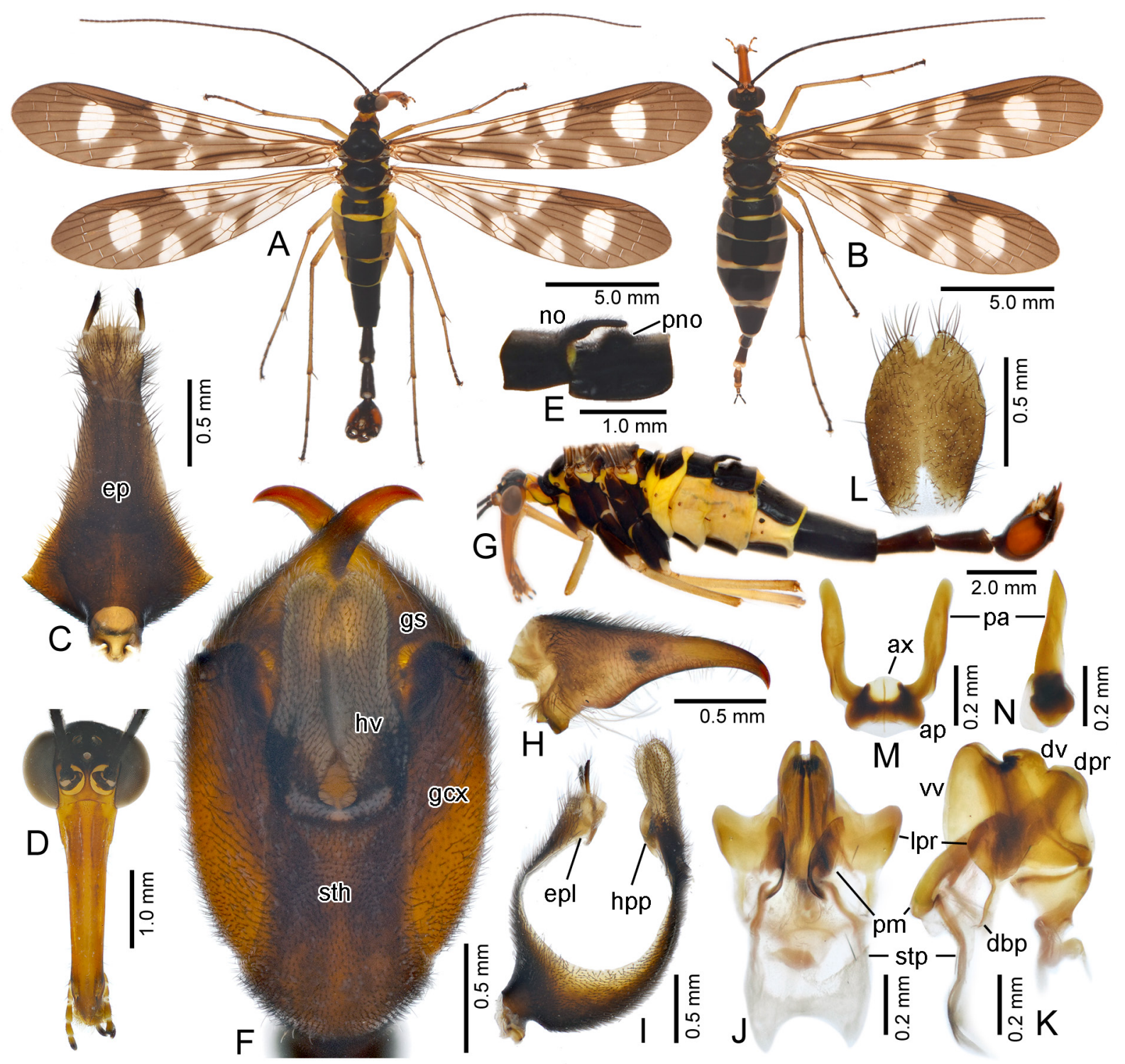

Fig. 5. Neopanorpa ocellaris (Navás, 1908). A, C-K. Male. A. Habitus, dorsal view. C. Epandrium, dorsal view. D. Head, frontal view. E. T3 and T4, left-lateral view. F. Genital bulb, ventral view. G. Habitus, left-lateral view. H. Left gonostylus, ventral view. I. Epandrium and hypandrium, leftlateral view. J-K. Aedeagal complex, ventral and right-lateral views, respectively. $-\mathbf{B}, \mathbf{L}-\mathbf{N}$. Female. B. Habitus, dorsal view. L. Subgenital plate, ventral view. M-N. Medigynium, ventral and right-lateral views, respectively. 
1.5 times as long as A5, slightly tapering toward truncated apex. A7 shorter than A6, evenly enlarged toward truncated apex; A8 shorter than A7, similar in shape but slightly beveled at apex.

Genitalia (Fig. 5C, F, H-K). Genital bulb dark reddish brown. Epandrium narrowing toward truncated apex, with small epandrial lobes. Hypandrium with broad basal stalk, and split into a pair of hypovalves at middle; hypovalves greyish brown, distinctly curled on lateral margin, and slightly overlapping on inner margin; hypandrial processes broad and rounded. Gonostylus shorter than gonocoxites, stout, with median tooth blunt triangular, and basal process subtrapezoidal; small triangular projection at base of basal process. Paramere blade-like, with membranous notch near base; slender dorsal bridge connected to base of lateral processes; basal stalk fused to form slightly sclerotized frame. Ventral aedeagal valves broad, laterally flattened with rounded apex; dorsal valves shorter than ventral valves; dorsal processes short and rounded; lateral processes short and blunt.

\section{Female - redescription}

Body coloration and patterns similar to those of males (Figs 4, 5B).

MeAsurements. $\mathrm{FL}=13.8-15.2 \mathrm{~mm}, \mathrm{FW}=3.0-3.4 \mathrm{~mm} ; \mathrm{HL}=12.5-13.6 \mathrm{~mm}, \mathrm{HW}=2.9-3.2 \mathrm{~mm}$.

Genitalia (Fig. 5L-N). Subgenital plate oval, with several long setae on apical portion, and emarginate in V-shape apically. Medigynium with long, twisted and narrowly spatulate posterior arms; axis subtriangular with a pair of short and rounded apodemes basally.

\section{Distribution}

Sikkim; China: western Guangxi and southeastern Guizhou.

\section{Comments}

For more than a century, $N$. ocellaris has only been known from a single female (holotype) collected from Sikkim in 1890 by Harmand, housed in the Muséum National d'Histoire Naturelle, Paris. The wings were illustrated by Navás (1908) and Esben-Petersen (1921), and the genitalia were dissected and illustrated by Rust \& Byers (1976). Based on the wing markings and genital morphology, N. ocellaris resembles several Indochinese species (Rust \& Byers 1976), but differs from other species from Sikkim and adjacent regions from the Himalayas.

The specimens obtained from China match the holotype in morphology basically, excluding one considerable dissimilarity: in the holotype, the marginal spot is unconnected with the basal band posteriorly, by contrast, in new material in this research, almost all individuals have the marginal spot fused with basal band posteriorly (Fig. 5 A-B). After careful examination of other characters, we treat this difference as an intraspecific variation. Neopanorpa ocellaris was published in the same article with $N$. cavaleriei (Navás, 1908), a species from Guizhou, China. In fact, $N$. ocellaris was found to be cohabitated with $N$. cavaleriei in Libo County, Guizhou (Ri-Xin Jiang, personal communication).

Neopanorpa lungtaushana Cheng, 1957

Fig. 6

Neopanorpa lungtaushana Cheng, 1957b: 32, figs 14-15 (type locality: Lung-Tau-Shan [now Longdoufeng], $600 \mathrm{~m}$ a.s.l., near Yiu Vill. above Tso-Kok-Wan [now Caojiaowan], Kwang-tung [now Guangdong], China).

Neopanorpa brevivalvae Chou \& Wang in Chou et al., 1988: 38, fig. 9 (type locality: Rucheng, Hunan, China), syn. nov. 


\section{Diagnosis}

This species can be recognized by the combination of the following features: 1) forewing with an additional short band between apical and pterostigmal bands (Fig. 6A-B); in males, 2) notal organ strongly arched dorsad at middle (Fig. 6D); 3) postnotal organ strongly raised and finger-like (Fig. 6D); 4) hypovalves distinctly reduced, shorter than one-fourth of hypandrium (Fig. 6E-F); 5) ventral aedeagal valves whitish with a pair of lateral hooks (Fig. 6F, H); and in females, 6) medigynium with broadly spatulate posterior arms, and a concealed axis (Fig. 6L).

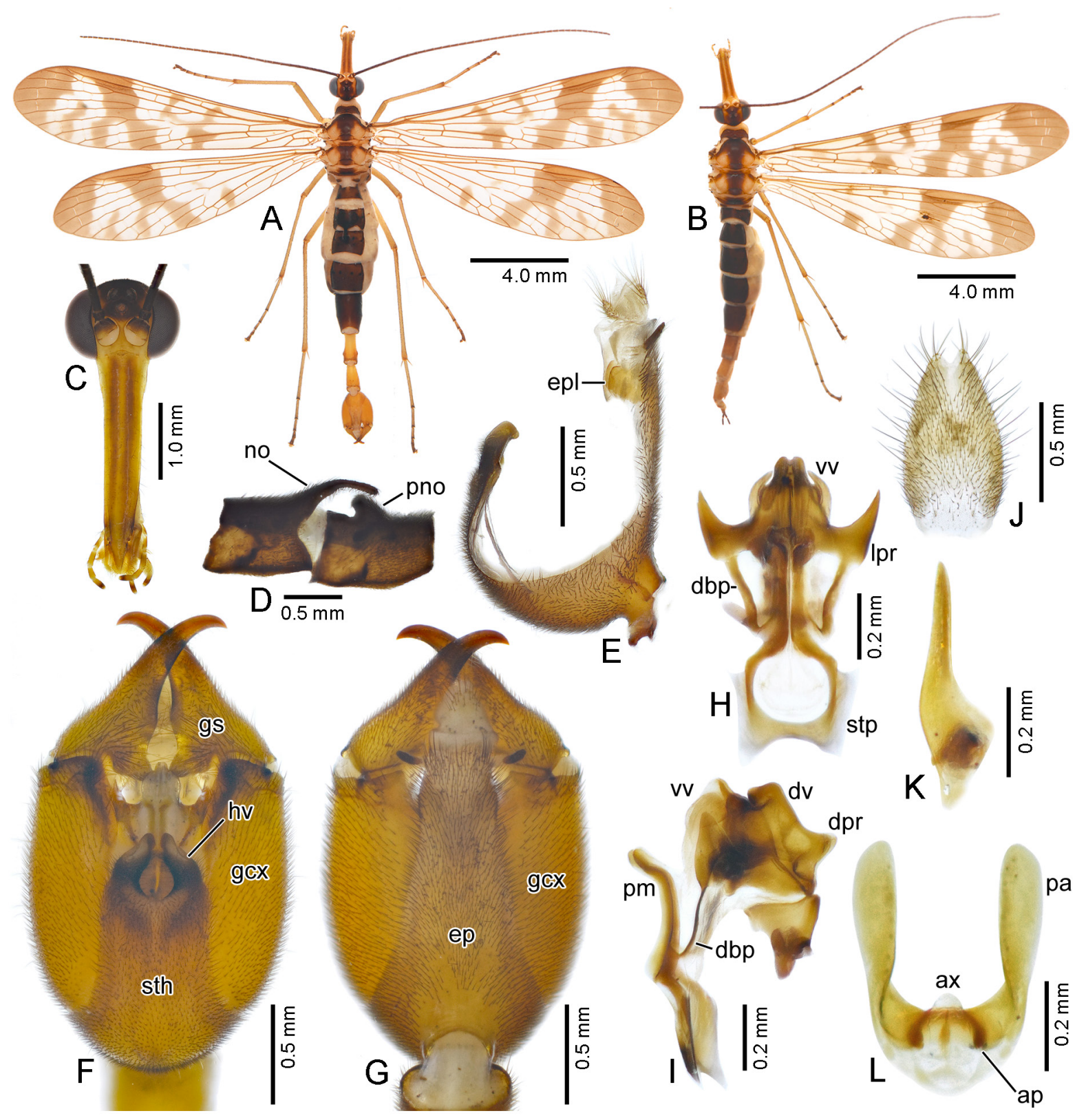

Fig. 6. Neopanorpa lungtaushana Cheng, 1957. A, C-I. Male. A. Habitus, dorsal view. C. Head, frontal view. D. T3 and T4, left-lateral view. E. Epandrium and hypandrium, right-lateral view. F-G. Genital bulb, ventral and dorsal views, respectively. H-I. Aedeagal complex, ventral and rightlateral views, respectively. - B, J-L. Female. B. Habitus, dorsal view. J. Subgenital plate, ventral view. $\mathbf{K}-\mathbf{L}$. Medigynium, right-lateral and ventral views, respectively. 


\section{Material examined}

CHINA - Hunan • $1 \hat{\jmath}$ (Holotype of Neopanorpa brevivalvae); Rucheng County; May 1984; ZhongDing Li \& Ri-Cheng Xiang leg.; NWAU • 8 ô $\widehat{\partial}, 2$ 우 ; Yizhang County, Mangshan Mountains; $1200 \mathrm{~m}$ a.s.1.; 21 May 2016; Ying Miao leg.; NWAU - Guangdong • 1 §, 1 क ; Lianzhou, Dadong Mountain;

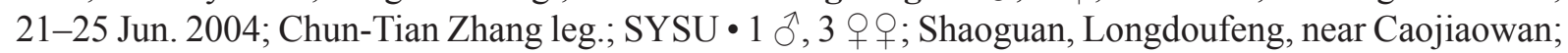

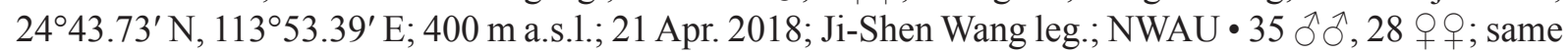

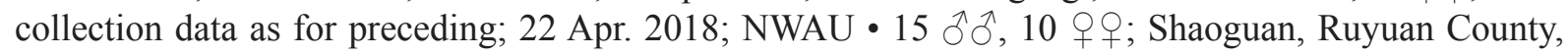
Nanling Mountains, Yunmen Mountain; 2449.34’ N, 113 ${ }^{\circ} 16.49^{\prime}$ E; 600 m a.s.1., 25 Apr. 2018; Ji-Shen

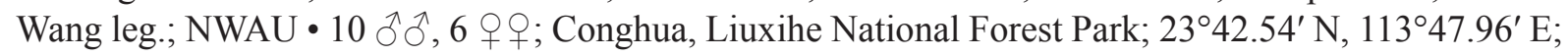
800 m a.s.l.; 30 Apr. 2018; Ji-Shen Wang leg.; NWAU.

\section{Description}

Measurements. Male: $\mathrm{FL}=13.5-14.8 \mathrm{~mm}, \mathrm{FW}=3.0-3.4 \mathrm{~mm} ; \mathrm{HL}=12.0-13.2 \mathrm{~mm}, \mathrm{HW}=2.8-3.2 \mathrm{~mm}$.; Female: $\mathrm{FL}=13.8-15.2 \mathrm{~mm}, \mathrm{FW}=3.0-3.4 \mathrm{~mm}$; $\mathrm{HL}=12.5-13.6 \mathrm{~mm}, \mathrm{HW}=2.9-3.2 \mathrm{~mm}$.

\section{Distribution}

China: southern Hunan and northern Guangdong.

\section{Comments}

The specimens collected from the type locality (Longdoufeng) were at first determined as $N$. brevivalvae based exclusively on the male genitalia, especially the greatly reduced hypovalves (Fig. 6F). The females, however, basically conform to the holotype of N. lungtaushana in morphology, especially in the broadly spatulate posterior arms in the medigynium (Fig. 6L).

Neopanorpa brevivalvae was described based on a male holotype, a female allotype, as well as one male paratype and one female paratype. According to the original descriptions and illustrations (Chou et al. 1988), the female medigynium bears an elongate axis extending beyond the main plate basally. However, the axes are greatly reduced in all the female specimens in this study. We reexamined the two female types of $N$. brevivalvae, and consider that they were mismatched with the males by Chou et al. (1988). Therefore, N. brevivalvae is here treated as a junior synonym of $N$. lungtaushana.

Neopanorpa furcula nom. nov.

Neopanorpa furcata Zhou, 2005: 385, fig. 10 (type locality: Xishui Nature Reserve, Guizhou, China), preoccupied by Neopanorpa furcata (Hardwicke, 1825).

\section{Etymology}

Furcula, a Latin noun, means 'a fork', pertaining to the original epithet "furcata" (forked, referring to the forked female medigynium, Zhou 2005).

\section{Discussion}

By adding two new species and a newly recorded species, and synonymizing one species, the species number of Neopanorpa from China is updated to 104.

Four closely related species are dispersed from the mountainous regions of western Sichuan through Yunnan and southward to Vietnam (Fig. 7): (1) N. setigera from Shimian, western Sichuan, China; (2) N. luojishana sp. nov. from Mt. Luoji, southern Sichuan, China; (3) N. longistipitata from Dali, northwestern Yunnan, China; and (4) N. dorsalis from Dalat, southern Vietnam. These four species closely resemble each other not only in the postnotal organs on T4-T6, but also in the reduced wing markings, the greatly elongated male notal organ, the basally constricted male A7 and A8, and the long 
spatulate posterior arms of the female medigynium. Similarly, this North-South distributional scenario can also be inferred between $N$. tibetensis from Tangmai, southeastern Tibet, and N. xingmini sp. nov. from western Yunnan, China (Fig. 7). Their speciation and current distributions were probably due to the North-South migration and isolation of their common ancestors along the Hengduan Mountains during the ice age, as Wang \& Hua (2018b) suggested.

As far as we know, no Himalayan species of Neopanorpa have been recorded from southern China and the Indochinese Peninsula, and vice versa (Byers 1965; Rust \& Byers 1976). The discovery of N. ocellaris from Guangxi and Guizhou, China suggests that there is a distributional gap in the Hengduan Mountains and the Yungui Plateau (Fig. 7). Further investigations in these regions are needed to improve our knowledge of the biogeographical and evolutionary implications of the genus Neopanorpa.

\section{Acknowledgements}

We express our sincere thanks to Gui-Lin Hu, Ri-Xin Jiang, Zhuo-Heng Jiang, Ning Li, Ying Miao, and Xing-Min Wang for collecting pecimens. We also thank Hong Pang and Bing-Lan Zhang for arranging the examination of collections in Sun Yat-Sen University. The field photograph of Neopanorpa ocellaris (Navás, 1908) was kindly provided by Wei-Liang Xie. We are grateful to two anonymous referees for valuable comments on the revision of the manuscript. This research was financially supported by the National Natural Science Foundation of China (Grant nos 31672341 and 31172125).

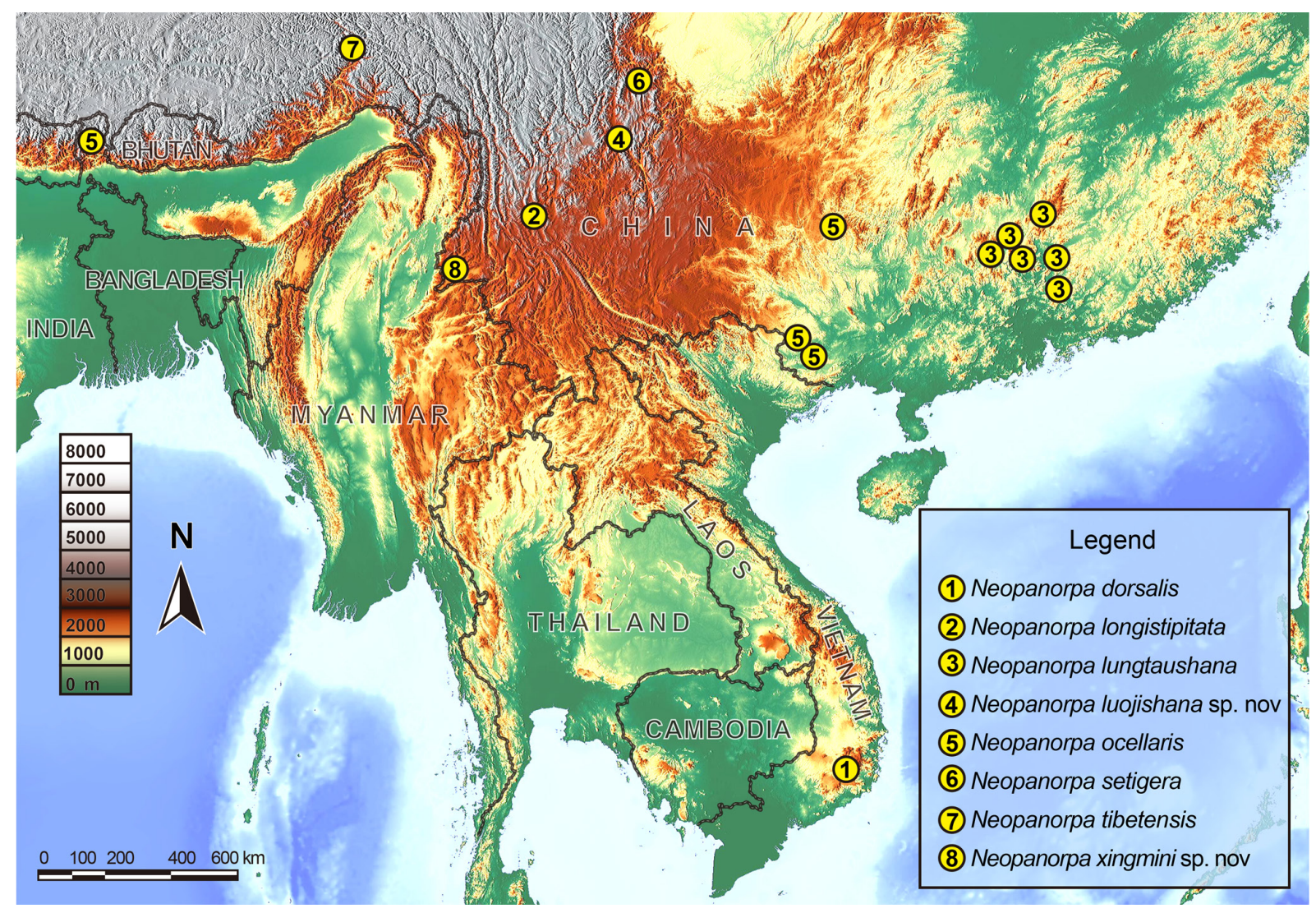

Fig. 7. Distribution map of Neopanorpa species discussed in this research. 


\section{References}

Bicha W.J. 2015. The scorpionflies (Mecoptera) of Indochina with the description of new species of Bittacus and Neopanorpa. Proceedings of the Entomological Society of Washington 117 (4): 435-451. https://doi.org/10.4289/0013-8797.117.4.435

Bicha W.J. 2018. Biodiversity of Mecoptera. In: Foottit R.G. \& Adler P.H. (eds) Insect Biodiversity: Science and Society, II: 705-720. John Wiley \& Sons, Hoboken.

https://doi.org/10.1002/9781118945582.ch23

Bicha W.J., Schiff N., Pham T.H., Lancaster A. \& Scheffler B. 2017. New species of Neopanorpa (Mecoptera) from Vietnam, with a key to the species of Mecoptera from Vietnam. Proceedings of the Entomological Society of Washington 119 (4): 529-544. https://doi.org/10.4289/0013-8797.119.4.529

Byers G.W. 1965. The Mecoptera of Indo-China. Pacific Insects 7 (4): 705-748.

Byers G.W. 1966. Mecoptera from Borneo and Tioman Islands. Pacific Insects 8 (4): 885-892.

Byers G.W. 1999. Thirteen new Panorpidae (Mecoptera) from northern Burma. Entomologica Scandinavica 30 (2): 197-218. https://doi.org/10.1163/187631200X00246

Byers G.W. \& Thornhill R. 1983. Biology of the Mecoptera. Annual Review of Entomology 28: 203-228. https://doi.org/10.1146/annurev.en.28.010183.001223

Chau H.C. \& Byers G.W. 1978. The Mecoptera of Indonesia: genus Neopanorpa. The University of Kansas Science Bulletin 51 (11): 341-405.

Cheng F.Y. 1957a. Revision of the Chinese Mecoptera. Bulletin of the Museum of Comparative Zoology at Harvard College 116 (1): 1-118.

Cheng F.Y. 1957b. Descriptions of new Panorpidae (Mecoptera) in the collection of the California Academy of Sciences. Memoirs of the College of Agriculture, National Taiwan University 5 (1): 27-33.

Chou I., Wang S.-M., Li Z.-D. \& Tong X.-W. 1988. New species of Mecoptera from Hunan Province (II)-Studies on the classification of Chinese Mecoptera (IV). Entomotaxonomia 10 (1-2): 31-42.

Esben-Petersen P. 1913. Mecoptera and Planipennia collected in Java by Edward Jacobson. Notes from the Leyden Museum 35: 225-236.

Esben-Petersen P. 1921. Mecoptera. Monographic revision: Collections zoologiques du Baron Edm. de Selys Longchamps. Catalogue systematique et descriptif 5: 1-172.

Gao C., Ma N. \& Hua B.-Z. 2016. Cerapanorpa, a new genus of Panorpidae (Insecta: Mecoptera) with descriptions of three new species. Zootaxa 4158 (1): 93-104.

http://doi.org/10.11646/zootaxa.4158.1.5

Hua Y., Tao S.-H. \& Hua B.-Z. 2018. An enigmatic new species of Panorpa Linneaus from the Bashan Mountains (Mecoptera, Panorpidae). ZooKeys 777: 109-118.https://doi.org/10.3897/zookeys.777.26056

Issiki S. 1933. Morphological studies on the Panorpidae of Japan and adjoining countries and comparison with American and European forms. Japanese Journal of Zoology 4: 315-416.

Ma N., Zhong W., Gao Q.-H. \& Hua B.-Z. 2012. Female genital plate diversity and phylogenetic analyses of East Asian Panorpidae (Mecoptera). Systematics and Biodiversity 10 (2): 159-178. https://doi.org/10.1080/14772000.2012.683459

Miao Y., Wang J.-S. \& Hua B.-Z. 2019. Molecular phylogeny of the scorpionflies Panorpidae (Insecta: Mecoptera) and chromosomal evolution. Cladistics 35: 385-400. https://doi.org/10.1111/cla.12357 
Mickoleit G. 1976. Die Genital- und Postgenitalsegmente der Mecoptera-Weibchen (Insecta, Holometabola) II. Das Dach der Geritalkammer. Zoomorphologie 85: 133-156. https://doi.org/10.1007/BF00281741

Miyamoto S. \& Makihara H. 1979. A new species of the genus Neopanorpa Weele from the Nansei Islands (Mecoptera). Esakia 14: 57-60.

Navás L. 1908. Neurópteros nuevos. Memorias de la Real Academia de Ciencias y Artes de Barcelona 6 (25): 401-423.

Penny N.D. \& Byers G.W. 1979. A check-list of the Mecoptera of the world. Acta Amazonica 9 (2): 365-388. http://dx.doi.org/10.1590/1809-43921979092365

Rust M.K. \& Byers G.W. 1976. The Mecoptera of India and adjacent regions. The University of Kansas Science Bulletin 51 (2): 19-90.

van der Weele H.W. 1909. Mecoptera and Planipennia of Insulinde. Notes from the Leyden Museum 31: $1-100$.

Wang J.-S. \& Hua B.-Z. 2017. An annotated checklist of the Chinese Mecoptera with description of male Panorpa guttata Navás, 1908. Entomotaxonomia 39 (1): 24-42.

https://doi.org/10.11680/entomotax.2017003

Wang M. \& Hua B.-Z. 2018a. A new species of Neopanorpa with an extremely long notal organ from Sichuan, China (Mecoptera, Panorpidae). ZooKeys 750: 131-140.

https://doi.org/10.3897/zookeys.750.23486

Wang M. \& Hua B.-Z. 2018b. High species diversity of the genus Neopanorpa (Mecoptera: Panorpidae) in Yunnan Province, China. Zootaxa 4483 (1): 36-66. https://doi.org/10.11646/zootaxa.4483.1.2

Wang J.-S. \& Hua B.-Z. 2019. Megapanorpa, a new genus with a single anal horn in males from Oriental China (Mecoptera: Panorpidae). Entomological Science 22 (1): 64-79. https://doi.org/10.1111/ens. 12336

Willmann R. 1989. Evolution und phylogenetisches System der Mecoptera (Insecta: Holometabola). Abhandlungen der Senckenbergischen Naturforschenden Gesellschaft 554: 1-153.

Zhou W.-B. 2005. Mecoptera. In: Jin D.-C. \& Li Z.-Z. (eds). Insects from Xishui Landscape: 383-387. Guizhou Science and Technology Publishing House, Guiyang.

Manuscript received: 23 March 2019

Manuscript accepted: 4 June 2019

Published on: 8 August 2019

Topic editor: Gavin Broad

Desk editor: Radka Rosenbaumová

Printed versions of all papers are also deposited in the libraries of the institutes that are members of the EJT consortium: Muséum national d'Histoire naturelle, Paris, France; Meise Botanic Garden, Belgium; Royal Museum for Central Africa, Tervuren, Belgium; Royal Belgian Institute of Natural Sciences, Brussels, Belgium; Natural History Museum of Denmark, Copenhagen, Denmark; Naturalis Biodiversity Center, Leiden, the Netherlands; Museo Nacional de Ciencias Naturales-CSIC, Madrid, Spain; Real Jardín Botánico de Madrid CSIC, Spain; Zoological Research Museum Alexander Koenig, Bonn, Germany; National Museum, Prague, Czech Republic. 